\title{
A comparison of the genetics of seedling and adult plant resistance to the spot form of net blotch (Pyrenophora teres f. maculata)
}

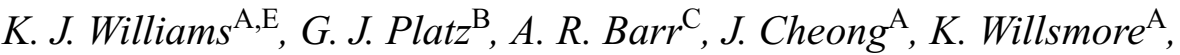 \\ M. Cakir ${ }^{\mathrm{D}}$, and H. Wallwork ${ }^{\mathrm{A}}$ \\ ${ }^{A}$ Cooperative Research Centre for Molecular Plant Breeding, South Australian Research and Development \\ Institute, Urrbrae, SA 5064, Australia. \\ ${ }^{B}$ QDPI, Agency of Food and Fibre Sciences, Hermitage Research Station, M/S 508, Yangan Road, Warwick, \\ Qld 4370, Australia. \\ ${ }^{\mathrm{C}}$ Department of Plant Science, Waite Campus, University of Adelaide, SA 5064, Australia. \\ DWA State Agricultural Biotechnology Centre, Division of Science and Engineering, Murdoch University, \\ Murdoch, WA 6150, Australia. \\ ${ }^{\mathrm{E}}$ Corresponding author; email: Williams.Kevin@saugov.sa.gov.au
}

\begin{abstract}
Spot form of net blotch (SFNB) (Pyrenophora teres f. maculata) is an economically damaging foliar disease of barley in many of the world's cereal-growing areas. The gene Rpt4 that confers seedling resistance to SFNB has been mapped on the long arm of chromosome 7H, but no genes for adult plant resistance (APR) have been identified. A lack of field resistance to SFNB in breeders' lines selected for Rpt4 led us to investigate the genetics of APR to this disease. Five doubled-haploid populations were phenotyped for seedling and adult plant reaction. Markers linked to Rpt4 explained a large part of the seedling variation, but little of the APR. In 2 mapped populations, major quantitative trait loci (QTLs) for APR distal to Rpt4 on chromosome 7H were identified. QTLs contributing to APR on chromosomes $4 \mathrm{H}$ or $5 \mathrm{H}$ were also identified in each population. Association of the $5 \mathrm{H}$ QTL with a gene for cereal cyst nematode resistance and the probable effect of this linkage on the historical development of cultivars with adult plant resistance to SFNB is discussed.
\end{abstract}

Additional keywords: Hordeum vulgare, disease resistance, APR, QTL mapping, genetics.

\section{Introduction}

The spot form of net blotch (SFNB), caused by the fungus Pyrenophora teres (Drechs.) forma maculata (Smedegaard-Petersen), is a foliar disease of barley found on crops grown in Europe, Canada, USA, South Africa, the Mediterranean region, and Australia (Tekauz and Buchannon 1977; Khan and Tekauz 1982; Karki and Sharp 1986; Louw et al. 1995). The spot form was differentiated from the net form of net blotch ( $P$. teres f. teres) by Smedegaard-Peterson (1971) on the basis of leaf symptom type. SFNB has been responsible for severe disease outbreaks in Canada (Tekauz and Buchannon 1977) and in Australia (Poulsen et al. 1999; Wallwork 2000). In Western Australia, Khan and Tekauz (1982) estimated that SFNB caused losses in grain yield of up to $25 \%$.

The use of resistant varieties is the most economic method of control of SFNB, although little is known about the genetics of adult plant resistance (APR) to the disease. The gene Rpt4 that confers seedling resistance to SFNB has been mapped on the long arm of chromosome $7 \mathrm{H}$ (Williams et al. 1999), and markers linked to a SFNB seedling resistance locus have been located on chromosome $2 \mathrm{H}$ by linkage with the $V r s l$ locus controlling spike type (Molnar et al. 2000).

In Australia, barley improvement programs have been breeding for resistance to SFNB but finding that there was a low recovery of progeny with APR equivalent to the donor parents. Marker-assisted selection (MAS) has been used extensively by those programs to rapidly introgress disease resistance genes into elite lines, and Rpt4, in particular, has been targetted using markers in several breeding programs. However, the phenotypic response to MAS for Rpt 4 has been disappointing, with the heritability of APR in Rpt4-positive material being relatively low. This has suggested that one or more unmapped genes, not detected in seedling assays of mapping populations, must contribute to APR in the field. This paper describes the mapping and validation of quantitative trait loci (QTLs) for adult plant resistance to 
SFNB, the mapping of seedling resistance to the Rpt4 locus in 4 additional genotypes, and an evaluation of the contribution of Rpt4 to APR in 5 populations.

\section{Materials and methods}

\section{Plant materials and disease screening}

Galleon/Haruna Nijo and Chebec/Harrington doubled-haploid (DH) populations have previously been described and mapped (Karakousis et al. 2003, this issue). The DH populations Mundah/Keel and VB9104/Dash were produced by Phil Davies (SARDI), Tilga/Tantangara by Barbara George-Jaeggli (QDPI), and CI9214/Stirling by Sue Broughton (Agriculture WA). Segregating $F_{2}$ populations were generated from the crosses Dairokkaku/WI3141 and Tilga/Keel. Additionally, a subset of single seed descent $\mathrm{F}_{7}$ lines derived from the $\mathrm{BC}_{1}$ population Gairdner/Keel//Gairdner was generated and used for a graphical genotyping study. The pedigrees and SFNB seedling and adult plant reaction of the lines used in this study are presented in Table 1.

\section{Seedling screening}

Keel/Gairdner, Dairokkaku/WI3141, Tilga/Keel, Galleon/Haruna Nijo, and Chebec/Harrington populations were phenotyped for seedling resistance in controlled-environment rooms as described in Williams et al. (1999), with ratings of 1 and 9 indicating highly resistant and highly susceptible plants, respectively. Tilga/Tantangara, CI9214/Stirling, and VB9104/Dash were screened by inoculating plants at the 2-leaf stage with a suspension of field-collected conidia at 15000 conidia $/ \mathrm{mL}$. Conidia were suspended in water and applied using an airbrush at $200 \mathrm{~mL} / \mathrm{m}^{2}$. Plants were incubated for $24 \mathrm{~h}$ at $19^{\circ} \mathrm{C}$ with an initial period of $14 \mathrm{~h}$ dark, and then transferred to a growth chamber (Tilga/Tantangara) or the glasshouse for symptom development. The growth chamber was maintained at $24 / 14^{\circ} \mathrm{C}$ and 12 -h photoperiod, and glasshouse temperatures ranged from 15 to $25^{\circ} \mathrm{C}$. Notes were taken $10-12$ days after inoculation using a scale of $1-9$ where 9 was very susceptible.

\section{Adult plant resistance}

The Galleon/Haruna Nijo population was sown as paired rows in an irrigated disease nursery at Turretfield in South Australia (SA) in 2002. Two incompletely duplicated replicates were assessed after flowering using a 1-9 scale reflecting disease severity. The VB9104/Dash population was sown as a single replicate in the Turretfield nursery in 2001. This population was also affected by scald (Rhynchosporium secalis), which made assessment of some plots more difficult than others. The Mundah/Keel population was assessed in naturally infected 4-row, 5-m plots at Tuckey, SA, in 2000. Tilga/Tantangara, VB9104/Dash, and CI9214/Stirling were assessed in a field nursery at Warwick, Qld, where the epidemic was initiated by artificial inoculation of susceptible spreader rows and promoted with sprinkler irrigation.

\section{Genetic mapping and graphical genotyping}

Mapping of Galleon/Haruna Nijo and Chebec/Harrington is described elsewhere in this issue (Karakousis et al. 2003). For other populations, DNA extraction was achieved using a DNA mini-prep method adapted from Rogowsky et al. (1991). Variations to the method were as described below. For DNA extraction, $750 \mu \mathrm{L}$ of extraction buffer and phenol-chloroform-isoamyl alcohol $(25: 24: 1)$ were used. The extraction buffer was $0.1 \mathrm{~m}$ Tris- $\mathrm{HCl}(\mathrm{pH} 8), 10 \mathrm{~mm}$ EDTA, $0.1 \mathrm{M} \mathrm{NaCl}$, and $1 \%$ sarkosyl. Deoxyribonucleic acid was precipitated by the addition of 0.1 vol. of $3 \mathrm{~m}$ sodium acetate $(\mathrm{pH} 4.8)$ and 1 vol. of propan-2-ol. Genotyping of DH lines and marker nomenclature used in the VB9104/Dash population were the same as reported elsewhere in this issue (Cakir et al. 2003). The map of the VB9104/Dash population contained 192 markers in 9 linkage groups at the time of this analysis. Partial maps were constructed of Tilga/Tantangara, Keel/Gairdner, and CI9214/Stirling, by genotyping 3 simple sequence repeats (SSRs) with known linkage to Rpt4.

SSR markers developed and mapped by Ramsay et al. (2000) were amplified using a 'touchdown' profile $\left(30 \mathrm{~s}\right.$ at $94^{\circ} \mathrm{C}, 30 \mathrm{~s}$ annealing, $1 \mathrm{~min}$ at $72^{\circ} \mathrm{C}$ ). The annealing temperature for the first cycle was $65^{\circ} \mathrm{C}$, reducing by $1^{\circ} \mathrm{C}$ per cycle for the next 10 cycles. The remaining 24 cycles were with annealing at $56^{\circ} \mathrm{C}$, in $10-\mu \mathrm{L}$ reaction mixes containing $20 \mathrm{~mm}$ Tris-HCL (pH 8.4), $50 \mathrm{~mm}$ KCL, $1.0 \mathrm{~mm}$ dNTP, $1.875 \mathrm{~mm}$ $\mathrm{MgCL}_{2}, 15 \mathrm{ng}$ of each primer, $0.5 \mathrm{U}$ of Taq DNA polymerase (Life Technologies), and $16 \mathrm{ng}$ template DNA. Polymerase chain reactions (PCRs) were performed in a PTC-225 (MJ Research) thermocycler. SSRs were separated on 1-mm-thick $6 \%$ polyacrylamide gels at constant $300 \mathrm{~V}$ for $3 \mathrm{~h}$. Gels were stained with ethidium bromide and visualised under UV light before photography.

Analysis of SFNB data by single-point regression analysis, simple interval mapping, composite interval mapping, and 2-locus interaction analysis was conducted using Map Manager QTX (Manly et al. 2001). A permutation test is used to establish the significance of the likelihood ratio statistics (LRSs) generated by the interval mapping procedures. The 'suggestive', 'significant', and 'highly significant' threshold values of the permutation test correspond to the 37th, 95th, and 99.9th percentiles, respectively (Manly et al. 2001). Bootstrap re-sampling was used to estimate a confidence interval for QTLs. Interval mapping was performed on multiple re-sampled datasets and the positions of maximum LRSs plotted as a histogram overlaying the interval mapping figure (Manly et al. 2001).

Graphical genotyping was conducted on lines developed from a backcrossing programme using $\mathrm{BC} 1$ families from the recurrent parent Gairdner and the donor parent Keel. MAS was used to select for the markers linked to cereal cyst nematode (CCN locus $\mathrm{Ha} 4$ ) and seedling resistance to spot form net blotch (SFNB locus Rpt4) from Keel, and key traits in the Gairdner recurrent parent were also selected by association with linked markers, namely, malt extract on $5 \mathrm{H}$ and $2 \mathrm{H}$, BYDV resistance on $3 \mathrm{H}$, and $\beta$-amylase isoform on $4 \mathrm{H}$ (see Fig. 3). In addition, phenotypic selection was applied for APR to SFNB (from Keel) and 'Gairdner type'. Forty-seven SSRs (Ramsay et al. 2000) distributed across the genome were used to genotype elite lines that had survived selection through to $\mathrm{F}_{7}$.

\section{Results}

Seedling resistance

Seedling and APR resistance scores for the parents of the populations used for this study are reported in Table 1.

Five DH populations from crosses between SFNB-resistant and susceptible lines were phenotyped using seedling bioassays (Table 2). Previously published data for the Galleon/Haruna Nijo population (Williams et al. 1999) are included for comparison. All populations except Galleon/Haruna Nijo and VB9104/Dash appeared to segregate for a single gene for seedling SFNB resistance $(P>0.05)$. Each of these populations was tested with molecular markers to determine if the resistance matched the known location of Rpt4 on chromosome $7 \mathrm{H}$.

The resistance in the CI9214/Stirling, Keel/Gairdner, and Tilga/Tantangara populations was observed to align with markers known to be linked to the Rpt4 locus on the long arm 
Table 1. Lines used in this study, their pedigrees, and seedling and field reaction to $P$. teres f. maculata 1 , most resistant; 9, most susceptible

\begin{tabular}{llcc}
\hline Line & Pedigree & Seedling reaction & Field reaction $^{\mathrm{A}}$ \\
\hline Chebec & Orge_Martin/Clipper//Clipper/3/Schooner & 3.5 & 6 \\
CI9214 & Korean land race & 1.5 & 3 \\
Dairokkaku & Japanese land race & 2.0 & 4 \\
Dash & Chad/Joline//Cask & 7.0 & 9 \\
Gairdner & Onslow/Tas83-587 & 7.0 & 8 \\
Galleon & Clipper/Hiproly//3*Proctor/CI3576 & 2.7 & 3 \\
Harrington & Klages/3/Gazelle/Betzes//Centennial & 7.0 & 8 \\
Haruna Nijo & Satsuko Nijo/(K-3/G-65) & 7.0 & 8 \\
Keel & CPI18197/Clipper//WI2645 & 2.0 & 2 \\
Stirling & Dampier//(A14)Prior/Ymer/3/Piroline & 6.0 & 7 \\
Tantangara & AB6/Skiff & 9.0 & 7 \\
Tilga & Forrest/Cantala & 1.5 & 4 \\
VB9104 & Europa/IBON\#7.148 & 3.0 & 4 \\
WI3141 & CCN4-10*WI2875-3-1D-17 & 1.0 & 7 \\
\hline
\end{tabular}

${ }^{\mathrm{A}}$ Approximate APR score, based on separate trials.

of chromosome $7 \mathrm{H}$ (Table 2). For the Chebec/Harrington DH population, the seedling SFNB reaction data were mapped with respect to 340 markers on its genetic map, with a major QTL also mapping to chromsome $7 \mathrm{H}$ at approximately the same location as Rpt4 (Table 2). Markers linked to Rpt4 explained $27-74 \%$ of the variance for seedling SFNB reaction in these populations (Table 2). The Rpt4-linked marker Bmag120 showed no association with seedling SFNB reaction scored independently by two groups at Turretfield in 2000 and Hermitage Research Station in 2001 in the VB9104/Dash population, although mapping of seedling resistance scores with respect to 192 molecular markers showed that distal markers on the long arm of chromosome $7 \mathrm{H}$ explained $9 \%$ of the observed variation (Table 2). Weaker QTLs for seedling resistance were also observed on chromosomes $1 \mathrm{H}$ and $3 \mathrm{H}$ in the VB9104/Dash population (not shown).

In order to examine the allelic relationships between Rpt4 and the seedling resistance expressed in Tilga and Dairokkaku, $100 \mathrm{~F}_{2}$ plants from each of the crosses
Dairokkaku/WI3141(Rpt4+) and Tilga/Keel(Rpt4+) were phenotyped for seedling SFNB reaction. No susceptible individuals were observed from either cross (data not shown).

\section{Adult plant resistance}

Five DH populations were phenotyped for SFNB APR in field plots. The relationship between seedling and APR was determined for each cross (Table 3). The slope of the linear regression between seedling and APR scores ranged from 0.39 in Galleon/Haruna Nijo $\mathrm{DHs}$ to 0.73 in the $\mathrm{Keel} /$ Gairdner single-seed descent lines.

A genetic map of the Galleon/Haruna Nijo cross was used to identify QTLs contributing to APR to SFNB. QTLs were identified on chromosomes $5 \mathrm{H}$ and $7 \mathrm{H}$ by simple interval mapping (Table 3). Bootstrap analysis showed that whereas the 5H QTLs had a clearly defined confidence interval within $12 \mathrm{cM}$ (not shown), the significant 7H QTLs were distributed along the long arm and many marker loci along the short arm of this chromosome also had a suggested

Table 2. Quantitative trait loci for seedling resistance to spot form of net blotch

\begin{tabular}{lclllcc}
\hline Population & $\begin{array}{c}\text { Segregation } \\
\text { (Res : Sus) }\end{array}$ & $\chi^{2 \mathrm{~A}}$ & Map location & Support interval & LRS $^{\mathrm{C}}$ (SIM) & $R^{2 \mathrm{D}}$ \\
\hline Galleon/Haruna Nijo & $34: 58$ & 6.2 & $7 \mathrm{H}: 117-141 \mathrm{cM}$ & AWBMA11-PSR129 & $98^{* *}$ & 65 \\
CI9214/Stirling & $55: 43$ & $1.46 \dagger$ & $7 \mathrm{H}: 112-145 \mathrm{cM}$ & AWBMS22-EBmac755 & $70.4^{* *}$ & 52 \\
Keel/Gairdner & $32: 35$ & $0.13 \dagger$ & $7 \mathrm{H}: 100-145 \mathrm{cM}$ & Bmag120-EBmac755 & $36.6^{* *}$ & 46 \\
Chebec/Harrington & $48: 64$ & $2.28 \dagger$ & $7 \mathrm{H}: 115-125 \mathrm{M}$ & PSR637b-P11M48-384 & $152^{* *}$ & 74 \\
Tilga/Tantangara & $55: 57$ & $0.03 \dagger$ & $7 \mathrm{H}: 100-112 \mathrm{cM}$ & AWBMS22-Bmag120 & $24.4^{* *}$ & 27 \\
VB9104/Dash & $8: 173$ & & $7 \mathrm{H}: 145-170 \mathrm{cM}$ & P13M47V300-Bmag135 & $16.1^{*}$ & 9 \\
\hline
\end{tabular}

*Significant $(P=0.05)$; **highly significant $(P=0.01)$ (Manly et al. 2001).

${ }^{\mathrm{A}}$ Results of Chi-square analysis; $\dagger$ segregation ratio does not differ from 1:1 expected for single gene in DH population $(P>0.05)$.

${ }^{\mathrm{B}}$ Approximate position on consensus map (Karakousis et al. 2003, this issue).

${ }^{\mathrm{C}}$ Likelihood ratio statistic for the association of the trait with this locus, as determined by simple interval mapping.

${ }^{\mathrm{D}}$ The amount of the total trait variance that would be explained by a QTL at this locus, as \%. 
Table 3. Quantitative trait loci for adult plant resistance to spot form of net blotch

\begin{tabular}{|c|c|c|c|c|c|c|}
\hline Population (and seedling/APR ${ }^{\mathrm{A}}$ ) & Map location ${ }^{\mathrm{B}}$ & Support interval & $\operatorname{LRS}(\mathrm{SIM})^{\mathrm{C}}$ & $R^{2 \mathrm{D}}$ & $\operatorname{LRS}(\mathrm{CIM})^{\mathrm{E}}$ & $R^{2}$ \\
\hline \multirow[t]{6}{*}{ Galleon/Haruna Nijo (0.39) } & 7H: & & & & & \\
\hline & $153-162 \mathrm{cM}$ & PSR547-ABC321 & $13.9^{*}$ & 18 & $12.9 \dagger$ & 13 \\
\hline & $125-135 \mathrm{cM}$ & ABG652b-AT/CCA 228 & $15.4^{*}$ & 20 & $14.7 \dagger$ & 15 \\
\hline & $167-172 \mathrm{cM}$ & AaWBI-Rlch4B & $19.7 * *$ & 27 & $15.2^{*}$ & 17 \\
\hline & $5 \mathrm{H}: 30-32 \mathrm{cM}$ & ABC254-Exo2a & $15.3^{*}$ & 19 & $9.6 \dagger$ & 10 \\
\hline & $4 \mathrm{H}: 70-73 \mathrm{cM}$ & WG114-BCD1130 & 0 & 0 & $7.0 \dagger$ & 8 \\
\hline \multirow[t]{6}{*}{ VB9104/Dash ${ }^{\mathrm{F}}(0.67)$} & 7H: $145-170 \mathrm{cM}$ & P13M47V300-Bmag135 & $33.7 * *$ & 17 & $37.6^{* *}$ & 17 \\
\hline & & & $26.8^{* *}$ & 14 & $28.1^{* *}$ & 13 \\
\hline & 5H: $20-40 \mathrm{cM}$ & P12M47D63-Bmag337 & 0.2 & 0 & $18.8^{* *}$ & 9 \\
\hline & & & 1.0 & 1 & 0.2 & 0 \\
\hline & $4 \mathrm{H}: 65-70 \mathrm{cM}$ & HVML03-P12M62V260 & $14.6^{*}$ & 8 & $17.2 * *$ & 8 \\
\hline & & & $18.7^{* *}$ & 10 & $21.7 * *$ & 10 \\
\hline CI9214/Stirling (0.70) & 7H: $112-145 \mathrm{cM}$ & AWBMS22-EBmac755 & $12.0^{*}$ & 35 & & \\
\hline Keel/Gairdner (0.73) & 7H: $112-145 \mathrm{cM}$ & AWBMS22-EBmac755 & $18.5^{* *}$ & 32 & & \\
\hline Tilga/Tantangara (0.67) & 7H: $100-112 \mathrm{cM}$ & Bmag120-AWBMS22 & $5.2 \dagger$ & 7 & & \\
\hline
\end{tabular}

${ }^{\text {A }}$ Slope of the linear regression line through seedling and APR scores for each population.

${ }^{\mathrm{B}}$ Approximate position on consensus map (Karakousis et al. 2003, this issue).

${ }^{\mathrm{C}}$ Likelihood ratio statistic for the association of the trait with this locus, as determined by simple interval mapping.; $\dagger$ suggestive $(P=0.63)$;

*significant $(P=0.05) ; *$ highly significant $(P=0.01)$ (Manly et al. 2001).

${ }^{\mathrm{D}} \mathrm{The}$ amount of the total trait variance that would be explained by a QTL at this locus, as $\%$.

${ }^{\mathrm{E}}$ Likelihood ratio statistic for the association of the trait with this locus, as determined by composite interval mapping (Manly et al. 2001).

${ }^{\mathrm{F}}$ Results in plain font are from the Turretfield 2000 trial, whereas those in italics are for the same population scored at Hermitage Research Station in 2001

$(P=0.63)$ contribution to SFNB APR (Fig. 1). Composite interval mapping (CIM) confirmed the significance of the $5 \mathrm{H}$ and $7 \mathrm{H}$ QTLs, as well as revealing a QTL of minor effect on chromosome $4 \mathrm{H}$. A 2-way interaction analysis at high stringency $(P=1.0 \mathrm{e}-6)$ revealed a positive interaction $(\mathrm{LRS}=35.6)$ between the most significant QTL on chromosome 7H and AWBMA28, the most distal marker of the short arm of chromosome $2 \mathrm{H}$ (not shown). To determine the effect of the APR QTL on chromosomes $5 \mathrm{H}$ and $7 \mathrm{H}$ identified in the Galleon/Haruna Nijo population, APR scores for DHs with both, either, or neither QTL were graphed. The QTLs provided greatest resistance when combined, suggesting that the 2 QTLs are additive in effect (Fig. 2).

Separate QTL analysis of the Turretfield and Hermitage field data for the VB9104/Dash population revealed a QTL with significant effect on APR on chromosome $7 \mathrm{H}$ of VB9104. This QTL was $20 \mathrm{cM}$ distal to Rpt4, but was at approximately the same location as the APR QTL from Galleon (Table 3). Another significant QTL for expression of APR at both sites was detected on chromosome $4 \mathrm{H}$ of VB9104. CIM confirmed the significance of the $4 \mathrm{H}$ and $7 \mathrm{H}$ QTLs. Additionally, CIM of the Turretfield data revealed a QTL of minor effect on chromosome $5 \mathrm{H}$, close to the APR QTL identified in Galleon (Table 3).

A further 3 populations were phenotyped for adult plant resistance, but were not fully mapped. Markers genotyped near the Rpt4 locus in DHs from CI9214/Stirling,
Keel/Gairdner, and Tilga/Tantangara explained less of the phenotypic variation for APR than for seedling resistance in these populations (Table 3 ).

SSR genotyping of 22 elite $\mathrm{F}_{7}$ lines from the Gairdner/Keel//Gairdner backcross population shows that, on average, $70 \%$ of alleles came from Gairdner, compared with the expectation, if no selection applied, of $75 \%$ (Fig. 3). Keel introgression segments are clearly visible around the chromosome $5 \mathrm{H}$ and $7 \mathrm{H}$ regions for $\mathrm{CCN}$ and SFNB resistance, respectively, with other segments on $1 \mathrm{H}, 2 \mathrm{H}$, and $4 \mathrm{H}$ from Keel also common. Large segments of Keel alleles on chromosome $7 \mathrm{H}$ were also evident in some lines (Fig. 3).

\section{Discussion}

Using a combination of candidate markers and $\mathrm{F}_{2}$ crosses, we have shown that the 5 barley lines CI9214, Keel, Chebec, Diariokkaku, and Tilga have SFNB seedling resistance at or near Rpt4, the gene originally identified in the cultivar Galleon (Williams et al. 1999) (Table 2). Each of these genotypes has quite different recent pedigrees, with apparently diverse sources of SFNB resistance. This suggests that to date, only one locus for seedling resistance to SFNB has been definitively mapped. Another locus has been tentatively mapped on chromosome $2 \mathrm{H}$ through association of seedling resistance-linked RAPD markers with the Vrs 1 locus for spike type (Molnar et al. 2000). All other references to net blotch resistance appear to relate to the net form of net blotch caused by $P$. teres $\mathrm{f}$. teres. In 


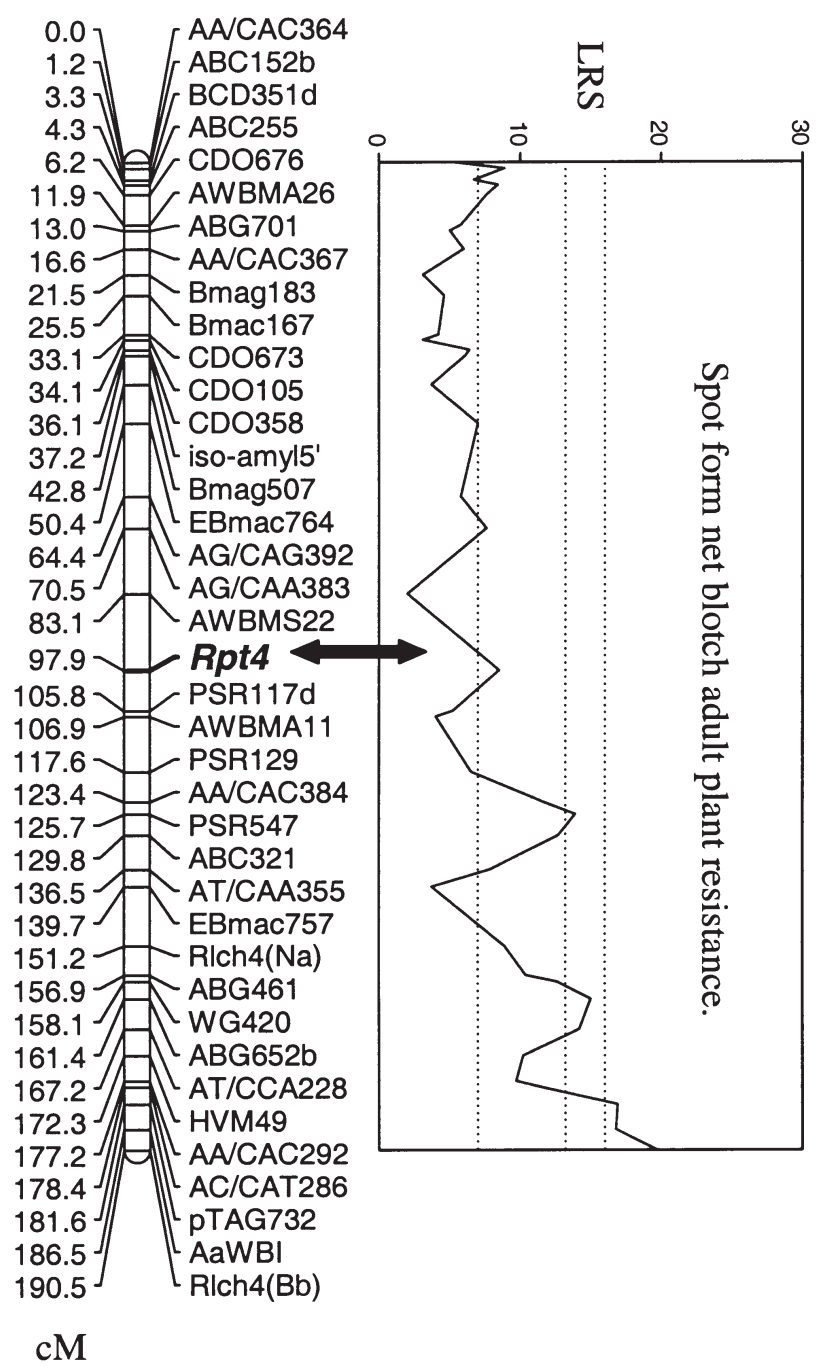

Fig. 1. Interval map of QTLs for adult plant resistance to spot form of net blotch on chromosome $7 \mathrm{H}$ from the Galleon/Haruna Nijo cross, compared with position of the seedling resistance gene Rpt4 on the genetic map (arrow). Vertical dotted lines indicate suggestive (9, $P=0.63)$, significant $(12, P=0.05)$, and highly significant (16, $P=0.001)$ thresholds for the likelihood ratio statistic (LRS; Manly et al. 2001) trace.

Australia, only one major pathotype of $P$. teres f. maculata has been found, so it cannot be determined if different alleles of Rpt4 exist.

Following marker-assisted selection of breeding lines for $R p t 4$, it was observed that field levels of resistance to SFNB were lower than expected. It was hypothesised that Rpt4 alone was not providing adequate APR and that supplementary genes were contributing to the higher levels of APR observed in some genotypes. Five DH populations were phenotyped for adult plant, as well as seedling, resistance to SFNB. Regression analysis showed that seedling resistance and APR were not highly correlated. In addition, QTL analysis showed that although Rpt4 contributed to APR, it had much less effect on disease suppression at this stage of plant growth than in seedlings.

When field resistance data were used for QTL analysis in the mapped Galleon/Haruna Nijo population, 3 closely linked QTLs with significant effects were observed on chromosome $7 \mathrm{H}$ and were derived from Galleon. None of the QTLs was at the same location as Rpt4, with the closest being $20 \mathrm{cM}$ distal (Fig. 1). In addition to the significant QTLs on the long arm of chromosome $7 \mathrm{H}$, the analysis suggested that loci distributed along the short arm of this chromosome were also having an effect on SFNB resistance. Another significant QTL for APR was detected on chromosome $5 \mathrm{H}$ in the Galleon/Haruna Nijo cross. This QTL is near the Ha4 gene for cereal cyst nematode (Barr et al. 1998). Many feed barley varieties bred for southern Australia descend from the Egyptian landrace CI3576. It is a carrier of the $\mathrm{Ha} 4$ allele, and the feed varieties Galleon and Barque were bred to carry $\mathrm{CCN}$ resistance by selecting for $\mathrm{Ha}$ 4. Keel was derived from a separate introduction from Egypt and has subsequently also been found to carry the $\mathrm{Ha} 4$ allele for $\mathrm{CCN}$ resistance $(\mathrm{K}$. J. Williams, unpublished work). All of these lines have excellent APR to SFNB and hence the finding that SFNB and CCN are linked fits well with breeders' experiences. Interestingly, Chebec derives its $\mathrm{CCN}$ resistance from the $\mathrm{Ha} 2$ gene on chromosome $2 \mathrm{H}$ (Kretschmer et al. 1997) and is susceptible as an adult plant, although it has seedling resistance, in common with Schooner, one of its parents.

When seedling and field data were used for QTL analysis in the mapped VB9104/Dash population, a QTL with statistically significant effects on both seedling and APR was observed on chromosome 7H of VB9104. This QTL was $20 \mathrm{cM}$ distal to the location of Rpt4, but was at approximately the same location as the APR QTL of Galleon. This raises the possibility that a locus closely linked to the Rpt4 seedling resistance gene contributes to APR, rather than Rpt4 itself.

Progeny of the VB9104/Dash cross exhibited a relatively low level of seedling resistance, with the strongest QTL mapping close to the strong APR QTL. It is likely that VB9104 does not contain Rpt4, but has several weak QTLs, which, when combined, provide some seedling resistance. A significant QTL for APR was detected on the long arm of chromosome $4 \mathrm{H}$ of VB9104, linked to the mlo-derived SSR marker HVMLO3. Intriguingly, the 4H QTL mapped in VB9104 and the 5H QTL mapped in Galleon were observed only in Galleon and VB9104, respectively, when composite interval mapping was performed to counteract the effect of the major QTL on chromosome $7 \mathrm{H}$. This indicates that up to 3 loci may be significantly associated with high levels of APR to SFNB. The data are also consistent with the Tilga/Tantangara study conducted by G. J. Platz and D. Poulsen (unpublished data), in which the APR/susceptible segregation ratio indicated the action of 3 independent genes. 


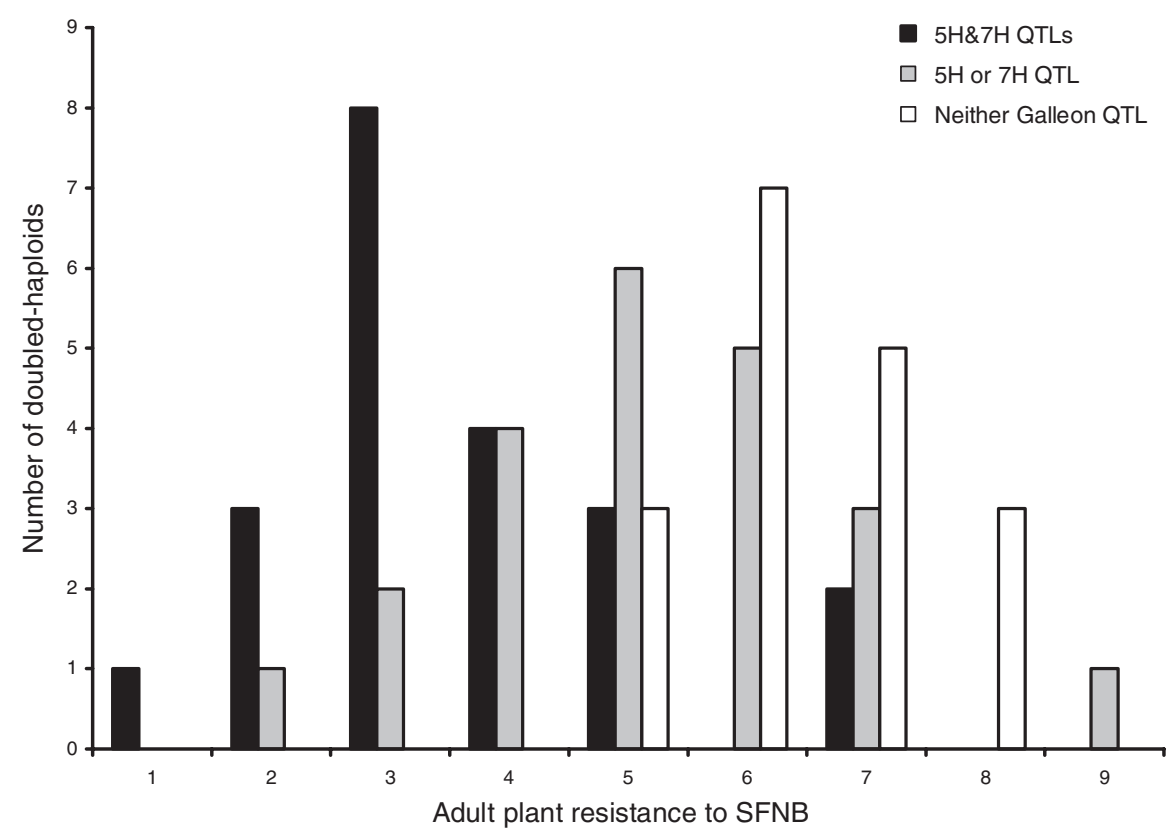

Fig. 2. Histogram of adult plant reaction to spot form of net blotch of Galleon/Haruna Nijo doubled-haploids with neither, one, or both resistance-associated QTL alleles identified in this study.

In an independent study, segregation analysis of the seedling and APR scores from Tilga/Tantangara also indicated the presence of a single gene conferring seedling resistance (G.J. Platz and D. Poulsen, unpublished data). It was observed that, whereas not all plants expressing seedling resistance demonstrated APR, all plants with APR had expressed seedling resistance. As seedling resistance in Tilga maps to the $7 \mathrm{H}$ region in the vicinity of $R p t 4$, the data are supportive of the conclusion that a locus in that region influences APR expression.

Plant growth characteristics can have a confounding effect on studies of APR. Kircherer et al. (2000) found that a QTL for leaf rust on chromosome $2 \mathrm{H}$ co-located with a QTL for heading date, and Spaner et al. (1998) found that a QTL for resistance to stem rust, scald, and net blotch on chromosome $4 \mathrm{H}$ was also close to genes for time of heading and maturity. The SFNB APR QTLs on $4 \mathrm{H}$ and $5 \mathrm{H}$ identified in this study map $\sim 20 \mathrm{cM}$ and $2 \mathrm{cM}$, respectively, from the peaks of 2 major QTLs for basic vegetative period, photoperiod response, and awn appearance on chromosomes $4 \mathrm{H}$ and $5 \mathrm{H}$ in the Galleon/Huruna Nijo population (Boyd et al. 2003, this issue). However, as there appears to have been no direct effects of maturity on disease scores in this population $\left(R^{2}=0.04\right)$, any association between resistance and these genes is likely to be incidental.

Graphical genotyping of Gairdner/Keel//Gairdner backcross lines was used as an alternative method of determining other regions of the genome with an effect on
SFNB APR. The effect of phenotypic selection for SFNB on the distribution of Keel alleles observed in the graphical genotyping study is speculative, due to the small number of marker alleles determined, but when combined with the results from the mapping and candidate marker studies reported in earlier sections, it seems likely that several regions of $7 \mathrm{H}, 5 \mathrm{H}$ (near $\mathrm{Ha} 4$ ), and possibly $1 \mathrm{H}, 2 \mathrm{H}$, or $4 \mathrm{H}$ are involved. These may confer APR to SFNB. Chromosomes $2 \mathrm{H}, 3 \mathrm{H}$, and $6 \mathrm{H}$ carry predominantly Gairdner-type alleles and Gairdner-type alleles are frequent around he regions where MAS was applied for Gairdner quality alleles.

In summary, a lack of field resistance to SFNB in breeders' lines selected for Rpt4 led us to investigate the genetics of APR to this disease. Five populations were phenotyped for seedling and adult plant reaction. Markers linked to Rpt4 explained a large part of the seedling variation, but little of the APR. In 2 mapped populations, major QTLs for APR distal to Rpt4 on chromosome 7H were identified. APR QTLs on $4 \mathrm{H}$ or $5 \mathrm{H}$ were also identified in each population. A small graphical genotyping study, coupled with breeders' experiences in variety development, supports these findings. Although a search for new seedling resistance loci has revealed that those lines with highly heritable seedling resistance all contain Rpt4, we now have identified some possible QTLs for APR that can be tested following marker-assisted selection in breeding for this important disease. 


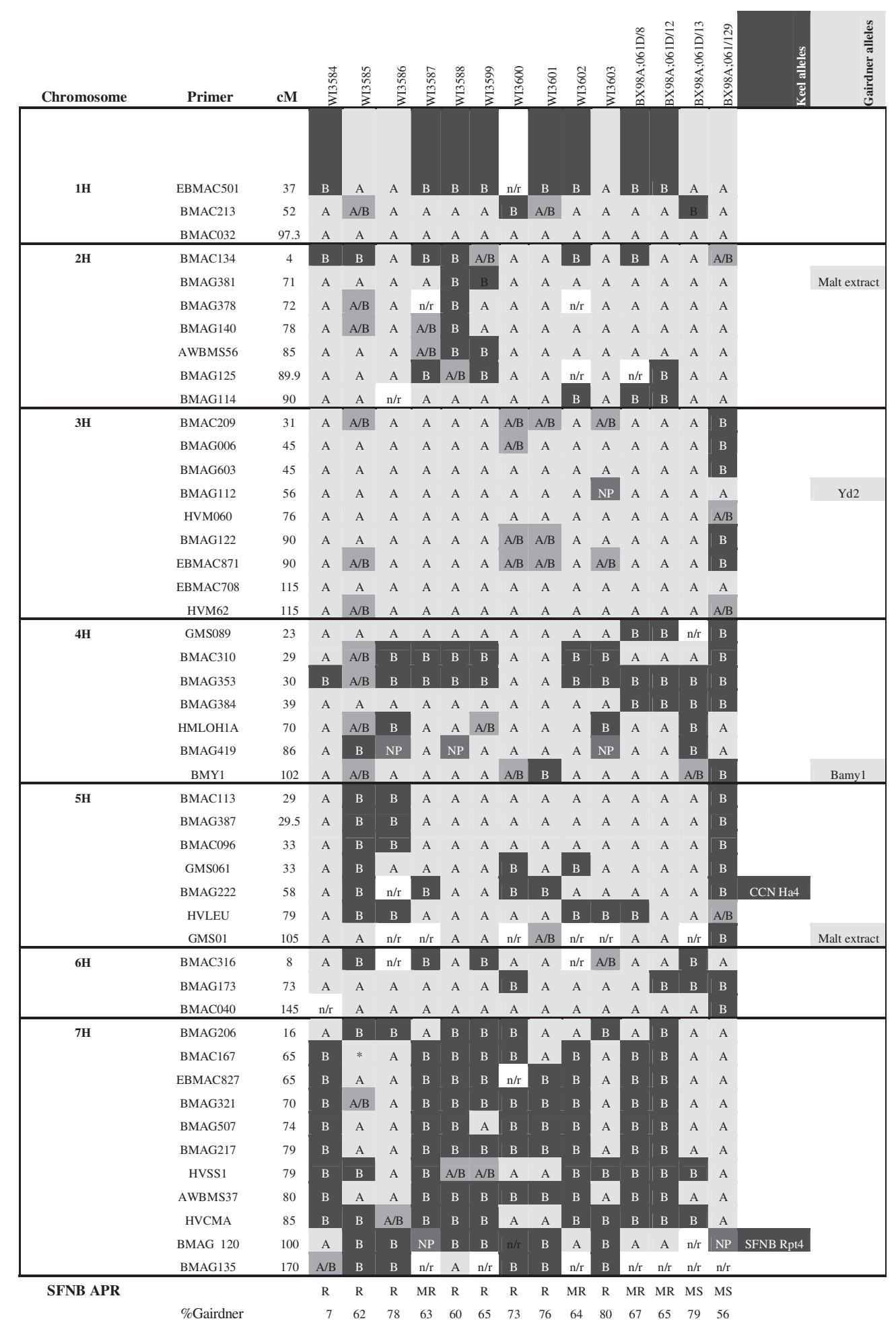

Fig. 3. Graphical genotypes of single-seed descent $\mathrm{F}_{7}$ lines derived from the $\mathrm{BC}_{1}$ population Gairdner/Keel//Gairdner selected for CCN locus Ha4 and SFNB locus Rpt4 from Keel, and malt extract on 5H and $2 \mathrm{H}$, BYDV resistance on $3 \mathrm{H}$, and $\beta$-amylase isoform on $4 \mathrm{H}$ from Gairdner, APR to SFNB from Keel, and 'Gairdner type'. Forty-seven SSRs (Ramsay et al. 2000) distributed across the genome were used to genotype elite lines that had survived selection through to $\mathrm{F}_{7}$. Key: A, Gairdner; B, Keel; A/B, heterozygous allele of Gairdner/Keel; NP, non-parental allele; n/r, no result. 


\section{Acknowledgments}

This work was funded in part by the Australian Grains Research and Development Corporation. Thanks to David Poulsen for critical reading of the manuscript, and Stewart Coventry for helpful comments.

\section{References}

Barr AR, Chalmers KJ, Karakousis A, Kretschmer JM, Manning S, Lance RCM, Lewis J, Jeffries SP, Langridge PJ (1998) RFLP mapping of a new cereal cyst nematode resistance locus in barley. Plant Breeding 11, 185-187.

Boyd WJR, Li CD, Grime CR, Cakir M, Potipibool S, Kaveeta L, Men S, Jalil Kamali MR, Barr AR, Moody DB, Lance RCM, Logue SJ, Raman H, Read BJ (2003) Conventional and molecular genetic analysis of factors contributing to variation in the timing of heading among spring barley (Hordeum vulgare L.) genotypes grown over a mild winter growing season. Australian Journal of Agricultural Research 54, 1277-1301.

Cakir M, Poulsen D, Galwey NW, Ablett GA, Chalmers KJ, Platz GJ, Park RF, Lance RCM, Panozzo JF, Read BJ, Moody DB, Barr AR, Johnston P, Li CD, Boyd WJR, Grime CR, Appels R, Jones MGK, Langridge P (2003) Mapping and QTL analysis of the barley population Tallon $\times$ Kaputar. Australian Journal of Agricultural Research 54, 1155-1162.

Karakousis A, Gustafson JP, Chalmers KJ, Barr AR, Langridge P (2003) A consensus map of barley integrating SSR, RFLP, and AFLP markers. Australian Journal of Agricultural Research 54, 1173-1185.

Karki CB, Sharp EL (1986) Pathogenic variation in some isolates of Pyrenophora teres f. sp. maculata on barley. Plant Disease $\mathbf{7 0 ,}$ 684-687.

Khan TN, Tekauz A (1982) Occurrence and pathogenicity of Drechslera teres isolates causing spot-type symptoms on barley in Western Australia. Plant Disease 66, 423-425.

Kircherer S, Backes G, Walther U, Jahoor A (2000) Localising QTLs for leaf rust resistance and agronomic traits in barley (Hordeum vulgare L.). Theoretical and Applied Genetics 100, 881-888. doi:10.1007/S001220051365.

Kretschmer JM, Chalmers KJ, Manning S, Karakousis A, Barr AR, Islam AKMR, Logue SJ, Choe YW, Barker SJ, Lance RCM, Langridge P (1997) RFLP mapping of the Ha2 cereal cyst nematode resistance gene in barley. Theoretical and Applied Genetics 94, 1060-1064. doi:10.1007/S001220050515.

Louw JPJ, Victor D, Crous PW, Holz G, Janse BJH (1995) Characterization of Pyrenophora isolates associated with spot and net type lesions on barley in South Africa. Journal of Phytopathology-Phytopathologische Zeitschrift 143, 129-134.
Manly KF, Cudmore RH, Meer JM (2001) Map Manager QTX, cross-platform software for genetic mapping. Mammalian Genome 12, 930-932. doi:10.1007/S00335-001-1016-3.

Molnar SJ, James LE, Kasha KJ (2000) Inheritance and RAPD tagging of multiple genes for resistance to net blotch in barley. Genome 43, 224-231. doi:10.1139/GEN-43-2-224.

Poulsen DME, Johnston RP, Platz GJ, Fox G, Kelly A, Sturgess JM, Fromm RL, Laufer MJ, Inkerman PA, Butler D (1999) Effects of foliar diseases on Northern Region grain production in the 1998 winter cropping season. In 'Proceedings of the 9th Australian Barley Technical Symposium, Melbourne, Australia'. pp. 2.20.01-05.

Ramsay L, Macaulay M, degli Ivanissivich S, MacLean K, Cardle L, Fuller J, Edwards K, Tuvesson S, Morgante M, Massari A, Maesti E, Marmiroli N, Sjakste T, Ganal M, Powell W, Waugh R (2000) A simple sequence repeat-based linkage map of barley. Theoretical and Applied Genetics 156, 1997-2005.

Rogowsky PM, Guidet FLY, Langridge P, Shepherd KW, Koebner RMD (1991) Isolation and characterization of wheat-rye recombinants involving chromosome arm 1DS of wheat. Theoretical and Applied Genetics 82, 537-544.

Smedegaard-Peterson V (1971) Pyrenophora teres f. maculata f. nov and Pyrenophora teres f. teres on barley in Denmark. Aarsskr. K. Vet-Landbohojsk 971, 124-144.

Spaner D, Shugar LP, Choo TM, Falak I, Briggs KG, Legge WG, Falk DE, Ullrich SE, Tinker NA, Steffenson BJ, Mather DE (1998) Mapping of disease resistance loci in barley on the basis of visual assessment of naturally occurring symptoms. Crop Science 38, $843-850$.

Tekauz A, Buchannon KW (1977) Distribution of and sources of resistance to biotypes of Pyrenophora teres in Western Canada. Canadian Journal of Plant Science 57, 389-395.

Wallwork H (2000) 'Cereal leaf and stem diseases.' (Grains Research and Development Corporation: Kingston, ACT)

Williams KJ, Lichon A, Gianquitto P, Kretschmer JM, Karakousis A, Manning S, Langridge P, Wallwork H (1999) Identification and mapping of a gene conferring resistance to the spot form of net blotch (Pyrenophora teres f. maculata) in barley. Theoretical and Applied Genetics 99, 323-327. doi:10.1007/S001220051239.

Manuscript received 30 January 2003, accepted 21 May 2003 